Article

\title{
Mechanical Performance of Eco-Friendly Concretes with Volcanic Powder and Recycled Concrete Aggregates
}

\author{
Viviana Letelier $^{1}{ }^{(\mathbb{D}}$, José Marcos Ortega ${ }^{2, *}$ (D) , Ester Tarela ${ }^{1}$, Pedro Muñoz ${ }^{3,4}$, \\ Bastián I. Henríquez-Jara ${ }^{1}$ and Giacomo Moriconi ${ }^{5}$ \\ 1 Departamento de Obras Civiles, Universidad de la Frontera, Av. Fco. Salazar, Temuco 01145, Chile; \\ viviana.letelier@ufrontera.cl (V.L.); ester.tarela@ufrontera.cl (E.T.); b.henriquez01@ufromail.cl (B.I.H.-J.) \\ 2 Departamento de Ingeniería Civil, Universidad de Alicante, Ap. Correos 99, 03080Alacant/Alicante, Spain \\ 3 Facultad de Ingeniería, Universidad Autónoma de Chile, 5 Poniente, 1670, Talca 3460000, Chile; \\ pmunozv@uautonoma.cl \\ 4 Escuela Superior de Ingeniería y Tecnología (ESIT), Universidad Internacional de La Rioja, \\ Av. de la Paz, 137, 26006Logroño, La Rioja, Spain \\ 5 Department of Science and Engineering of Matter, Environment and Urban Planning, \\ Università Politecnica delle Marche, Via Brecce Bianche, 60131 Ancona, Italy; g.moriconi@univpm.it \\ * Correspondence: jm.ortega@ua.es; Tel.: +34-96-5903-400 (ext. 1167)
}

Received: 15 July 2018; Accepted: 20 August 2018; Published: 27 August 2018

\begin{abstract}
At present, reducing the environmental impact of the construction industry is a major subject of study. In terms of the use of recycled concrete aggregates (RCA), most recently conducted studies have shown that the use of a limited percentage of those aggregates does not significantly affect the properties of concretes. This work analysed the mechanical properties of medium-strength concretes with a high contribution to sustainability, where cement and natural coarse aggregates (NCA) were partially replaced by volcanic powder (VP) and RCA, respectively. Three mixing ratios of VP replacement were tested in concretes without RCA and concretes with $30 \%$ RCA replacing NCA. Results show that when VP is used without RCA, up to $10 \%$ of the cement can be replaced by VP without a significant loss in the mechanical properties. When a combination of $5 \% \mathrm{VP}$ and 30\% RCA is used, the weakness of the recycled concrete is strengthened, obtaining stronger concretes than a control concrete with no recycled materials. Finally, the greenhouse gas assessment showed that the simultaneous incorporation of VP and RCA reduces $\mathrm{CO}_{2}$ emissions produced in the manufacture of concrete by up to $13.6 \%$.
\end{abstract}

Keywords: volcanic powder; recycled aggregates; eco-friendly concrete; sustainability; mechanical performance; Young's modulus

\section{Introduction}

The worldwide growth of the construction industry has produced an increase in the need for raw materials as well as the generation of a large amount of construction and demolition waste every year. This has made the construction industry an important source of unavoidable environmental problems [1]. In order to reduce the impact of these problems, many countries have adopted sustainable development programs based on the use of recycled materials [2].

Concrete is one of the most widely used construction materials globally. Therefore, as a way to reduce its harmful environmental impacts, many studies have focused on analysing the effects of the replacement of different concrete components with recycled materials [3,4]. In that line, due to the high levels of $\mathrm{CO}_{2}$ emissions generated by cement production [5], it is considered that one of the most 
effective ways to reduce the harmful environmental impacts of concrete is by replacing part of the cement with Supplementary Materials derived from waste [6-8]. This would reduce costs, energy and residue volume [9].

Several studies have been performed on the use of volcanic ash powder (VP) in blended cement and concretes. Siddique [10] concluded that VP satisfies the ASTM C618 requirements for use as pozzolanic material. Usually, significant losses in compressive strength are observed when the percentage of VP used is over $10 \%$, leading to the general recommendation of replacing cement with VP only up to a 15-20\% maximum, to limit the strength losses [11,12]. Moreover, it has been pointed out that the use of low percentages of VP is beneficial for concrete durability, producing materials more resistant to seawater attack [13], carbonation and chloride ion ingress [11]. Hossain [14] concluded that the use of up to $20 \%$ VP replacement provides blended cement with a higher setting time and low heat of hydration.

On the other hand, the over-use of natural coarse aggregates (NCA) in civil engineering applications can have a significant environmental impact, reducing its availability within a territory. The use of recycled concrete aggregates (RCA), including productive chains of natural and RCA, can increase the sustainability of the aggregate acquisition process $[15,16]$. In this vein, several researchers have studied the effects of using RCA in concrete manufacturing in recent decades [17-19]. The main issue when RCA are used replacing natural aggregates is the old mortar that remains attached to their surfaces. The presence of old mortar weakens the final material because two weak interfaces must be considered: an old one between the old mortar and the aggregate and a new one between the RCA and the new cement mixture [18]. The amount and quality of the old mortar determine the quality of the interfaces, having an important influence on the mechanical behaviour of the final material [20-22]. One common way to control the strength losses produced by the use of RCA is to limit the percentages of the aggregates replaced. Several authors [23-25] agree that low amounts of RCA do not significantly modify the properties of the recycled concrete and, therefore, the use of up to $30 \%$ of RCA in structural concrete manufacturing is permitted by several European technical regulations [26].

The use of both residues in concrete manufacturing, RCA and VP, has been widely studied separately but the effect of their simultaneous application is yet unknown. Therefore, the aim of this study is to analyse concretes with the simultaneous replacement of NCA by RCA and cement by VP, with respect to their effects on the mechanical properties of the sustainable final concretes. Different mixtures have been considered with the aim of optimizing the mixture so as to minimize the strength losses while trying to maximize the amount of replaced materials. Furthermore, a greenhouse gas (GHG) assessment of the studied concrete series was performed as well as an analysis of the SUB-RAW index [27], which includes the embodied energy and $\mathrm{CO}_{2}$ footprint parameters, in order to evaluate the replacement of the concrete raw materials.

\section{Experimental Procedure}

\subsection{Cement and VP}

The targeted compressive strength after 28 curing days was set at $30 \mathrm{MPa}$. A pozzolanic cement equivalent to ASTM type P cement was used.

VP from the Calbuco volcano has been used to replace different amounts of cement in concrete manufacturing. Calbuco $\left(41^{\circ} 20^{\prime} \mathrm{S}, 72^{\circ} 37^{\prime} \mathrm{W}, 2003\right.$ m.a.s.l.) is an active stratovolcano located in the southern Andes in Chile, near the cities of Ensenada and Puerto Montt. Its last subplinian eruption occurred on 22 and 23 April 2015 with a total calculated bulk tephra fall deposit volume of $0.27 \mathrm{~km}^{3}$. The erupted materials are porphyritic basaltic andesite $\left(\sim 55 \mathrm{wt} . \%\right.$ of $\left.\mathrm{SiO}_{2}\right)$ [28]. The fall mainly affected the northeast area of the volcano and the finest ash was deposited over southern Chile and Argentinian Patagonia. A grain size distribution analysis revealed particle sizes from $3 \mu \mathrm{m}$ up to $350 \mu \mathrm{m}$, with a 
variable distribution depending on the distance from the origin [29]. After sieving, the VP particles under $75 \mu \mathrm{m}$ were selected and used.

The chemical analysis and the physical properties of cement and VP are shown in Table 1.

Table 1. Physical and chemical properties of cement and volcanic powder (VP).

\begin{tabular}{ccc}
\hline Composition & Cement & VP \\
\hline $\mathrm{SiO}_{2}$ & $38.06 \%$ & $57.76 \%$ \\
$\mathrm{Al}_{2} \mathrm{O}_{3}$ & $8.88 \%$ & $14.54 \%$ \\
$\mathrm{CaO}$ & $40.92 \%$ & $8.27 \%$ \\
$\mathrm{Fe}_{2} \mathrm{O}_{3}$ & $2.83 \%$ & $11.00 \%$ \\
$\mathrm{SO}_{3}$ & $2.33 \%$ & - \\
$\mathrm{MgO}$ & $1.59 \%$ & $2.44 \%$ \\
$\mathrm{Na}_{2} \mathrm{O}$ & $1.75 \%$ & $2.41 \%$ \\
$\mathrm{~K}_{2} \mathrm{O}$ & $1.62 \%$ & $2.14 \%$ \\
$\mathrm{TiO}_{2}$ & - & $1.42 \%$ \\
Density & $2688 \mathrm{~kg} / \mathrm{m}^{3}$ & $2450 \mathrm{~kg} / \mathrm{m}^{3}$ \\
Blaine surface & $461 \mathrm{~m}^{2} / \mathrm{kg}$ & $285 \mathrm{~m}^{2} / \mathrm{kg}$ \\
area & & \\
\hline
\end{tabular}

The main component of the VP is silica, around $57 \%$ and it presents traces of alumina, iron oxide and calcium oxide (34\%). The Blaine fineness of the VP is $285 \mathrm{~m}^{2} / \mathrm{kg}$ and its density is $2450 \mathrm{~kg} / \mathrm{m}^{3}$. The grain size distribution of the VP is shown in Figure 1.

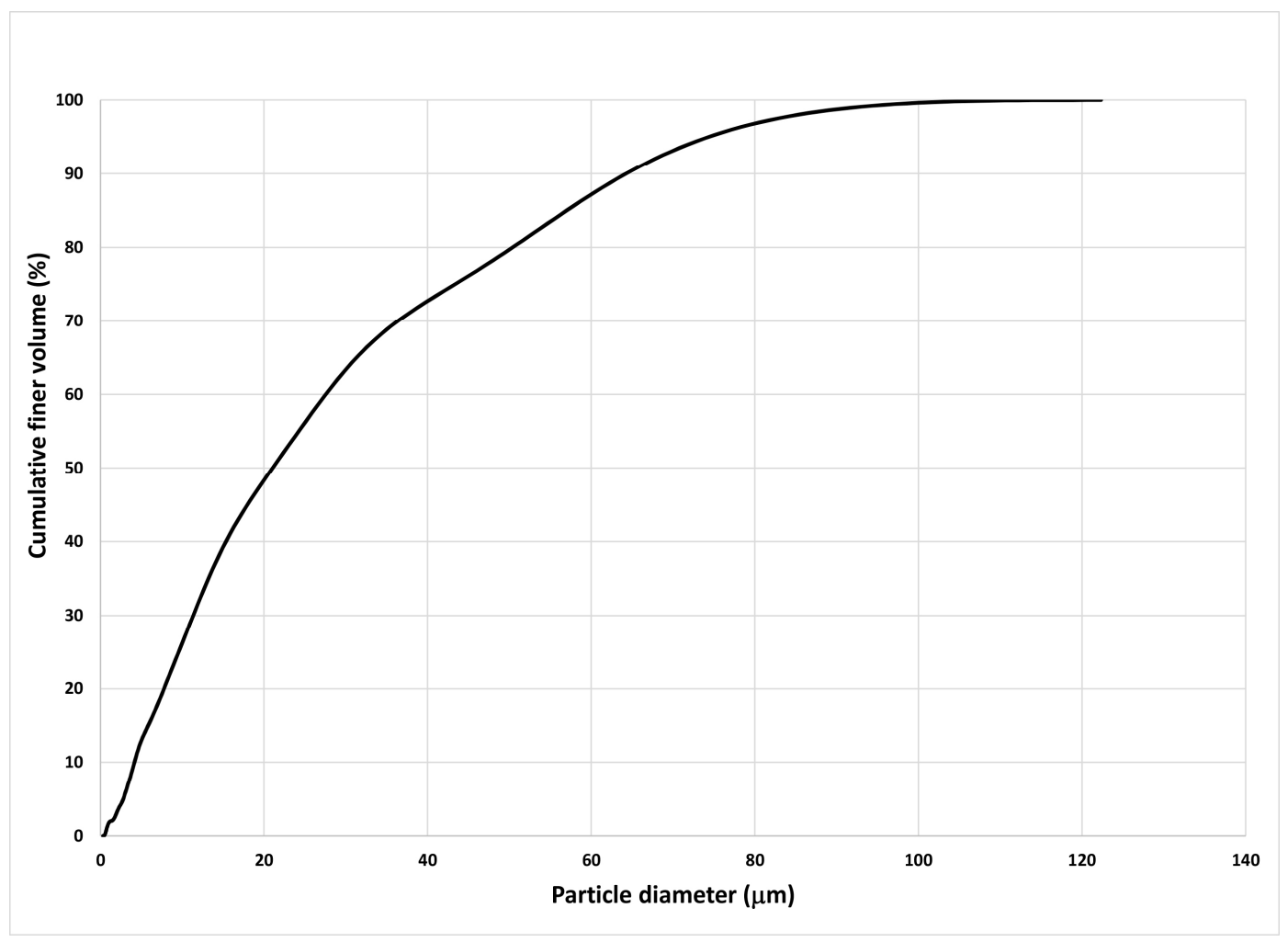

Figure 1. Grain size distribution of VP.

The Blaine values (see Table 1) were obtained according to the ASTM C204 specifications. VP presents lower specific surface values than cement due to a lower mean particle size.

The scanning electron microscopy (SEM) analysis of the VP (Figure 2) showed that it is formed by irregularly shaped particles with quite smooth surfaces according to the low surface area reported in 
Table 1. Also, the energy-dispersive X-ray spectroscopy (EDX) of the VP (Figure 3) was consistent with the chemical analysis in Table 1.

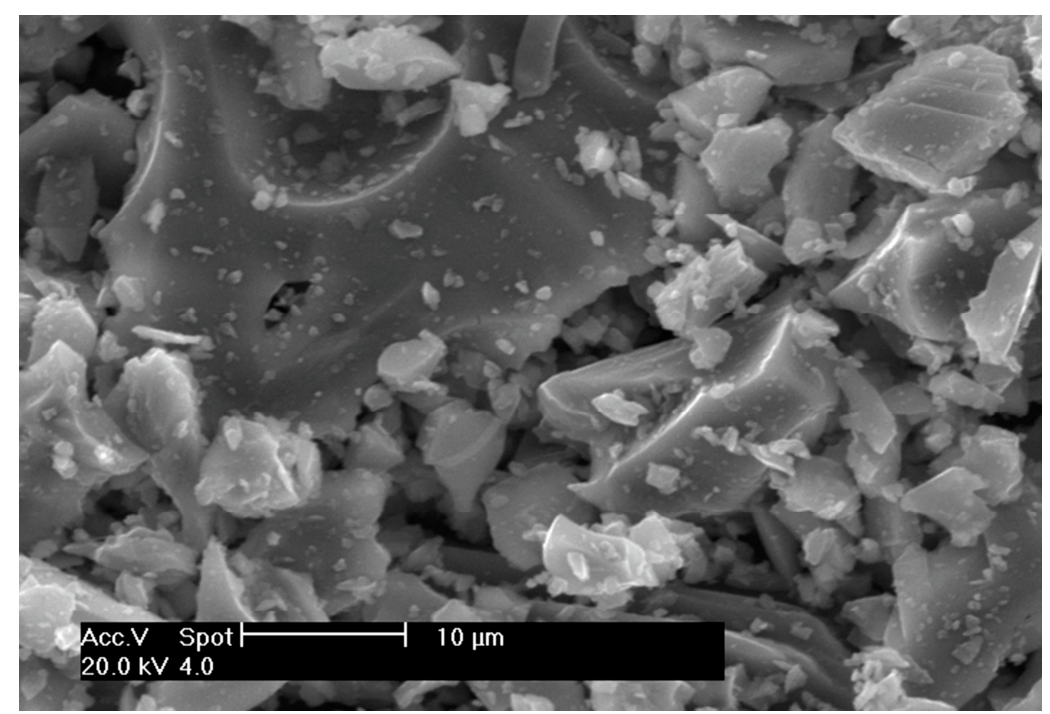

Figure 2. Scanning electron microscopy (SEM) micrographof the VP.

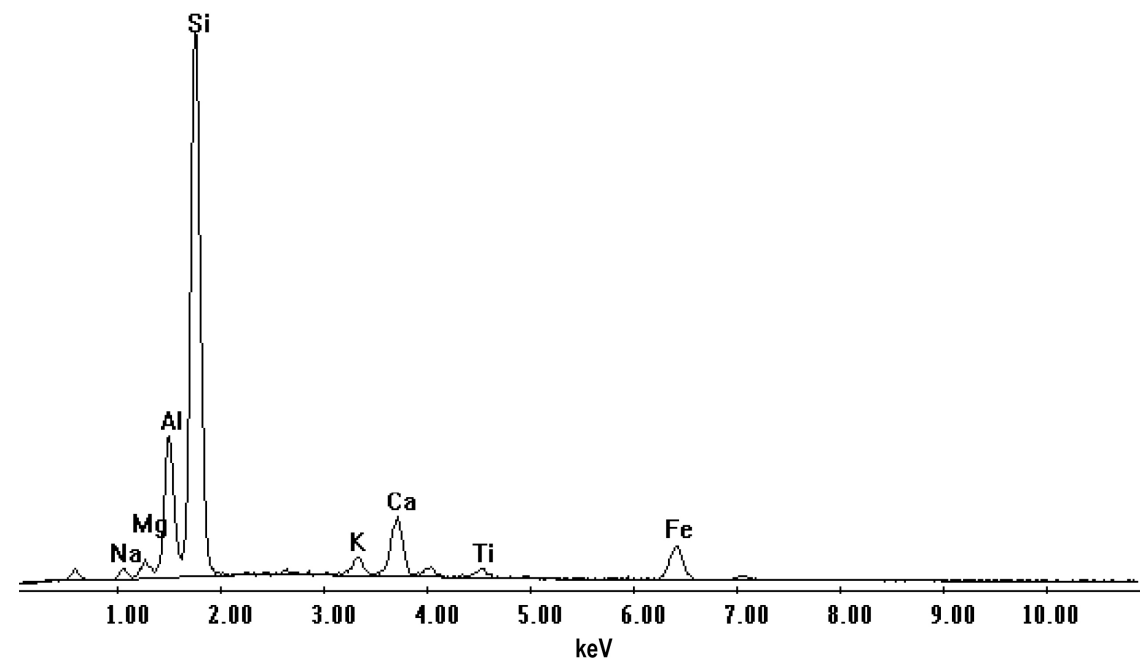

Figure 3. Energy dispersive x-ray spectroscopy (EDX) analysis of the VP.

\subsection{Natural and Recycled Concrete Aggregates}

The RCA were obtained from precast concrete debris. The compressive strength of the source was estimated around $17 \mathrm{MPa}$.

A thermal treatment previously proposed by several authors [30] was used to measure the amount of mortar adhered to the RCA surfaces. The methodology consisted of a thermal shock to remove the mortar from the RCA to enable its quantification. The percentages of mortar found for each of the sizes, $6.3 \mathrm{~mm}, 9.5 \mathrm{~mm}$ and $12.5 \mathrm{~mm}$, were $54 \%, 53 \%$ and $50 \%$, respectively. Consistent with previous studies, it was found that the smaller fraction tends to present a higher percentage of mortar [31].

The SEM analyses of the RCA are presented in Figure 4 which shows both the mortar and the RCA as well as the microfissures caused by the grinding process [32]. The EDS analysis of the RCA (Figure 5) shows that the RCA are composed mainly of silica, calcium and aluminium. 


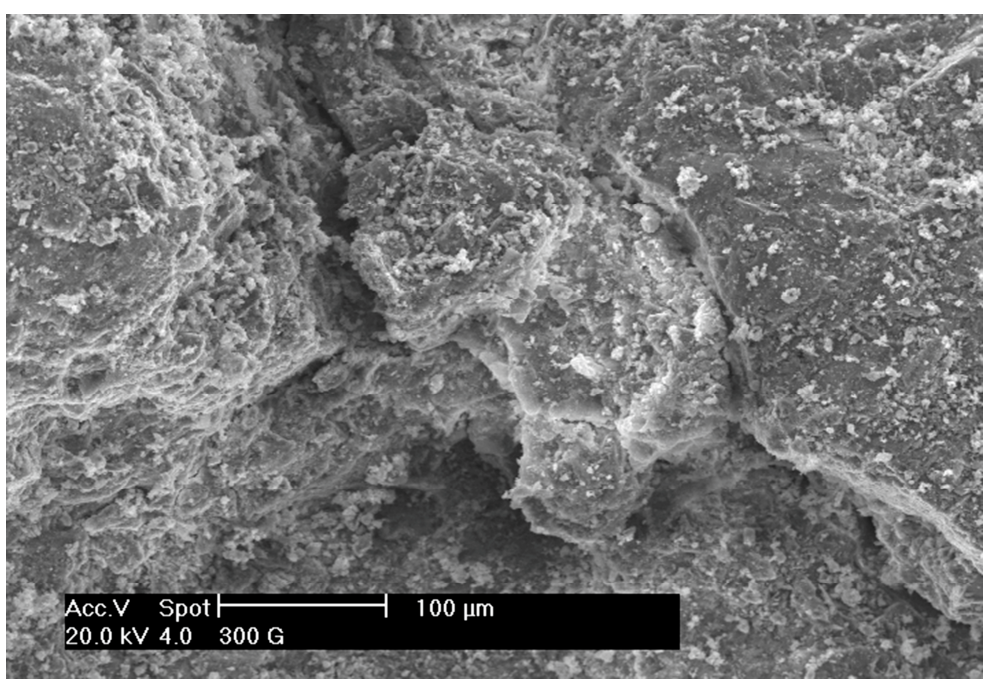

Figure 4. SEM micrographof the RCA.

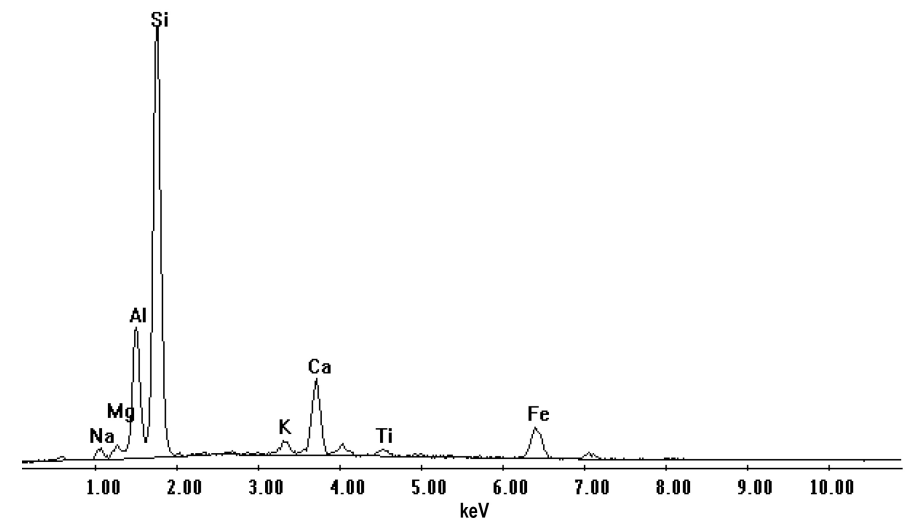

Figure 5. EDX analysis of the RCA.

The results obtained for the physical properties, calculated following the ASTM C127-15 and the ASTM C128-15, are shown in Table 2. The nominal sizes considered were $12.5 \mathrm{~mm}, 9.5 \mathrm{~mm}$ and $6.3 \mathrm{~mm}$. The density of the RCA presented values of $6 \%$ lower than the NCA. This decay in the density values is due to the presence of old mortar on their surfaces. The porosity of this mortar also produced an increase of around 2.5 times in the water absorption values.

Table 2. Physical properties of coarse aggregates.

\begin{tabular}{cccccc}
\hline Aggregates & Size (mm) & $\begin{array}{c}\text { Bulk Specific Gravity }(\text { Saturated } \\
\text { Surface Dry, SSD) }\left(\mathbf{k g} / \mathbf{m}^{\mathbf{3}}\right)\end{array}$ & $\begin{array}{c}\text { Bulk Specific } \\
\text { Gravity }\left(\mathbf{k g} / \mathbf{m}^{\mathbf{3}}\right)\end{array}$ & $\begin{array}{c}\text { Apparent Specific } \\
\text { Gravity }\left(\mathbf{k g} / \mathbf{m}^{\mathbf{3}}\right)\end{array}$ & $\begin{array}{c}\text { Water } \\
\text { Absorption (\%) }\end{array}$ \\
\hline \multirow{3}{*}{ NCA } & $6.3-9.5$ & 2678 & 2629 & 2765 & 1.9 \\
& $9.5-12.5$ & 2687 & 2642 & 2767 & 1.7 \\
& $12.5-19$ & 2699 & 2661 & 2765 & 1.4 \\
\hline \multirow{2}{*}{ RCA } & $6.3-9.5$ & 2510 & 2390 & 2720 & 5.0 \\
& $9.5-12.5$ & 2530 & 2430 & 2720 & 4.4 \\
& $12.5-19$ & 2530 & 2440 & 2700 & 4.0 \\
\hline
\end{tabular}

\subsection{Sample Preparation and Testing}

The main goal of this study is to analyse the effects of the simultaneous use of RCA and VP on the mechanical properties of concrete. Therefore, three different types of samples were tested: concrete containing both VP and RCA, concrete containing only VP and a control concrete (CC) made with natural aggregates and no VP. To assess the effects of VP as a partial cement replacement, 
a constant water/binder ratio of 0.42 was used for all the concretes. Three different amounts of VP were considered, $5 \%, 10 \%$ and $15 \%$ and evaluated in both types of concrete, the one with no RCA and the one with $30 \%$ of RCA.

The concrete mixture proportions of the manufactured specimens are shown in Table 3 together with the slump test results.

After keeping the samples under laboratory conditions for $24 \mathrm{~h}$, they were de-moulded and immersed in water with lime at a constant temperature of $23 \pm 3{ }^{\circ} \mathrm{C}$ during the curing time. In the case of the compressive strength, 4 different curing times were considered: 7, 14, 28 and 90 days. A hydraulic press with a maximum capacity of $3000 \mathrm{kN}$ was used to determine the compressive strength of each cylindrical sample with $150 \mathrm{~mm}$ diameter and $300 \mathrm{~mm}$ height, following the standard ASTM C39/C39M. The static modulus of elasticity was determined following the ASTM C469 in identical samples after 28 curing days. Prismatic specimens $150 \times 150 \times 530 \mathrm{~mm}$ cured for 28 and 90 days were used to test the flexural strength following the ASTM C78 specifications. For all the tests, three samples from each series were used.

Table 3. Concrete mixture proportions.

\begin{tabular}{|c|c|c|c|c|c|c|c|}
\hline Series & $\begin{array}{c}\text { NA } \\
(6.3-19.0 \mathrm{~mm})(\mathrm{kg})\end{array}$ & $\begin{array}{c}\text { RCA } \\
(6.3-19.0 \mathrm{~mm})(\mathrm{kg})\end{array}$ & Cement (kg) & VP (kg) & Sand (kg) & Water (L) & Slump $(\mathrm{cm})$ \\
\hline $\mathrm{CC}$ & 920 & - & 382.0 & - & 877 & 203 & 3.0 \\
\hline VP10-RCA0 & 920 & - & 343.8 & 38.2 & 877 & 203 & 2.0 \\
\hline VP15-RCA0 & 920 & - & 324.7 & 57.3 & 877 & 203 & 6.0 \\
\hline VP5-RCA30 & 644 & 276 & 362.9 & 19.1 & 877 & 203 & 1.0 \\
\hline
\end{tabular}

\subsection{Greenhouse Gas Assessment}

The $\mathrm{CO}_{2}$ emission factors (in $\mathrm{kgCO}_{2} / \mathrm{kg}$ ) and the embodied energy for the concrete components studied are provided in Table 4 . Those corresponding to the cement production, NCA and RCA were obtained from the "Inventory of Carbon and Energy" [33]. For the sand, a factor $0.014 \mathrm{kgCO}_{2} / \mathrm{kg}$ was considered and its embodied energy was not considered because the sand was not compared with other material. Regarding the VP, the energy consumption of the grinding machine model Gilson Testing Screen TS-1F and the average $\mathrm{CO}_{2}$ emissions, provided by the Organisation for Economic Co-operation and Development (OECD) [34], were estimated by $\mathrm{kWh}$ associated with the generation of electricity $\left(0.432 \mathrm{kgCO}_{2} / \mathrm{KWh}\right)$. In relation to the GHG and energy consumption, the contribution of VP was negligible compared to cement.

The emissions associated with the transport of cement and VP were assumed to be similar, so they were not included in the comparison. However, those emissions play an important role in the case of RCA [33], because the transport of RCA generally produces fewer emissions than NCA, especially when the latter come from great distances [35,36]. Here, a distance of $15 \mathrm{~km}$ was considered for RCA transport and $100 \mathrm{~km}$ for NCA and sand transport, which is a common situation in big cities such as Paris, according to Fraj and Idir [35]. The emissions due to transport are approximately $0.14 \mathrm{kgCO}_{2} /$ ton $\cdot \mathrm{km}$ according to the database of Conversion Factors for Greenhouse Gas of the UK government [37].

Table 4. Greenhouse gas (GHG) and embodied energy factors.

\begin{tabular}{cccc}
\hline Raw Material & $\mathrm{KgCO}_{2} / \mathbf{k g}$ (in Production Stage) & $\mathbf{K g C O}_{2} / \mathbf{k g}$ (Transport) & $\mathbf{M J} / \mathbf{k g}$ (in Production Stage) \\
\hline Cement & 0.82 & - & 4.6 \\
VP & 0.006 & - & 0.0045 \\
NCA & 0.005 & 0.014 & 0.1 \\
RCA & 0.012 & 0.002 & 0.25 \\
Fine aggregate (sand) & 0.014 & 0.014 & - \\
\hline
\end{tabular}


In order to evaluate how much more sustainable the raw materials studied are compared to the common ones, the SUB-RAW Index [27] was used, which is defined as:

$$
S U B-R A W \text { index }=\left[\log \left(E E_{\text {raw }}\right)-\log \left(E E_{\text {sub }}\right)+\log \left(C F_{\text {raw }}\right)-\log \left(C F_{\text {sub }}\right)\right] / 2
$$

where $E E_{\text {raw }}$ represents the embodied energy of the original material $(\mathrm{MJ} / \mathrm{kg}) ; E E_{\text {sub }}$ represents the embodied energy of the proposed material (MJ $/ \mathrm{kg}) ; C F_{\text {raw }}$ represents the $\mathrm{CO}_{2}$ emissions of the original material $(\mathrm{kg} / \mathrm{kg}) ; C F_{\text {sub }}$ represents the $\mathrm{CO}_{2}$ emissions of the proposed material $(\mathrm{kg} / \mathrm{kg})$.

This index can have values between -9 and 9 and the more positive its value, the higher the relative sustainability of the proposed material.

\section{Results and Discussion}

\subsection{Density}

The dry density of the different concrete series tested after 28 curing days is shown in Figure 6.

All the series containing VP in the absence of RCA showed slightly higher densities than the CC. Due to the filler effect of the VP, its particles fill the pores of the material, releasing the water trapped in them and increasing the density and compactness of the concrete [38]. According to Silva et al. [38], the materials used as cement replacement have a limited filler capacity. Once this limit is reached, the exceeding particles start to occupy the volume of the replaced material (cement in this case), rendering the density dependent only on the relative densities of the cement and the new material. The density of the VP is lower than that noted for the cement, so once the filler limit is reached, the density of the material starts to decrease again, explaining the values obtained in Figure 6 .

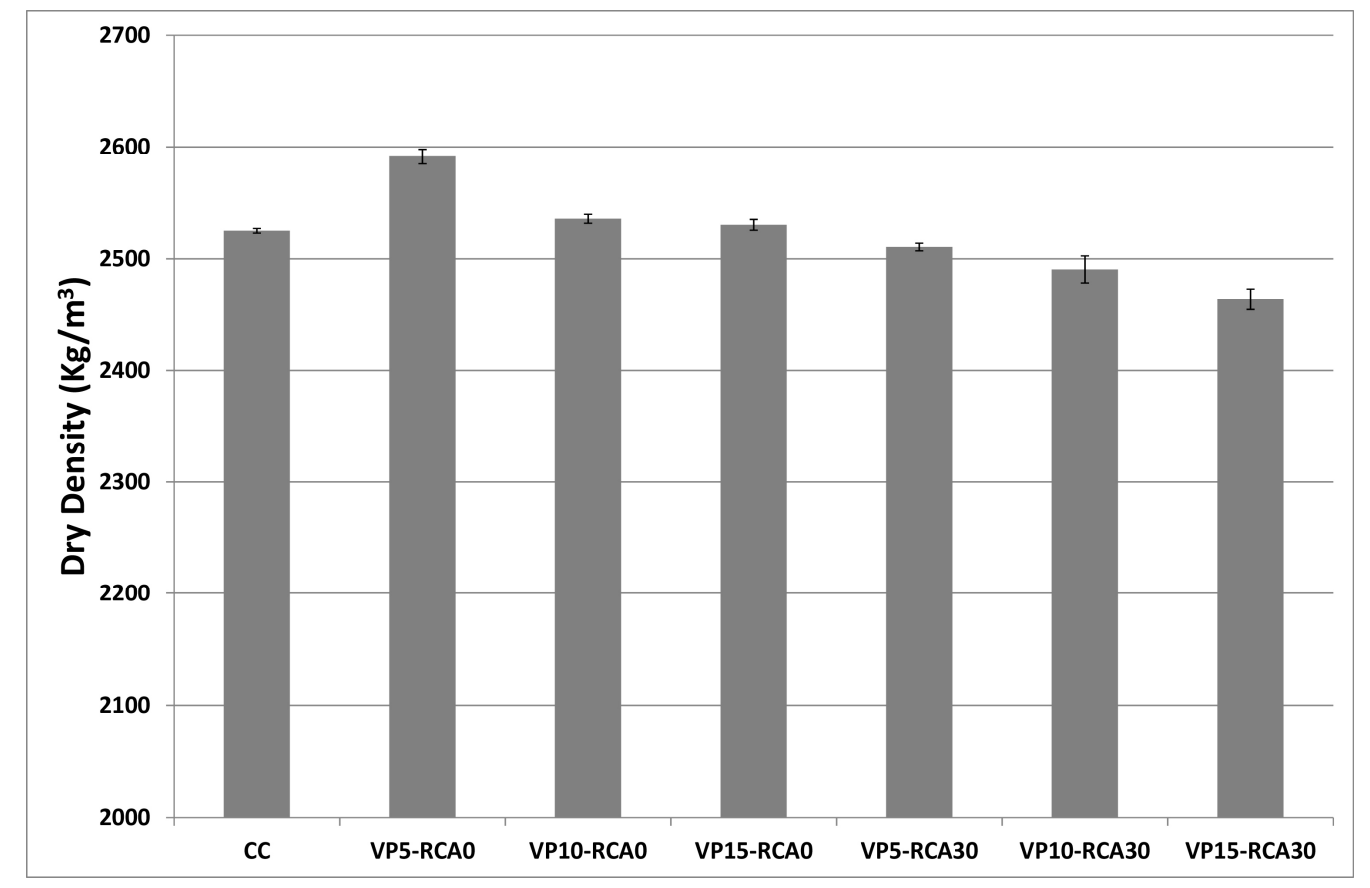

Figure 6. Dry density after 28 curing days.

The series that contain VP and RCA presented lower densities than the CC, with values that decreased with the rise in the VP content. The RCA have lower densities than the NCA they are replacing and the same occurs with the VP and the cement. 


\subsection{Compressive Strength}

Results are displayed in Table 5.

Table 5. Mechanical properties of tested specimens.

\begin{tabular}{|c|c|c|c|c|c|c|c|c|}
\hline & & $\mathrm{CC}$ & VP5-RCA0 & VP10-RCA0 & VP15-RCA0 & VP5-RCA30 & VP10-RCA30 & VP15-RCA30 \\
\hline \multirow{8}{*}{$\begin{array}{l}\text { Compressive } \\
\text { Strength (MPa) }\end{array}$} & 7 days & 19.05 & 20.45 & 14.24 & 14.03 & 20.32 & 15.23 & 15.04 \\
\hline & $\mathrm{Std} \%$ & 3.7 & 3.1 & 3.3 & 3.3 & 1.9 & 3.0 & 0.9 \\
\hline & 14 days & 24.22 & 21.09 & 24.19 & 16.86 & 26.45 & 19.26 & 19.43 \\
\hline & $\mathrm{Std} \%$ & 6.9 & 6.9 & 1.6 & 5.2 & 4.5 & 5.1 & 1.7 \\
\hline & 28 days & 32.63 & 31.11 & 27.64 & 21.77 & 34.58 & 28.42 & 25.68 \\
\hline & Std $\%$ & 3.1 & 1.5 & 3.7 & 6.4 & 1.9 & 5.4 & 2.7 \\
\hline & 90 days & 41.03 & 42.02 & 39.77 & 32.48 & 47.25 & 33.56 & 38.10 \\
\hline & $\mathrm{Std} \%$ & 1.6 & 0.2 & 3.9 & 1.8 & 0.1 & 5.0 & 2.7 \\
\hline \multirow{4}{*}{$\begin{array}{l}\text { Flexural Strength } \\
\quad(\mathrm{MPa})\end{array}$} & 28 days & 4.7 & 4.2 & 3.3 & 3.7 & 3.6 & 3.3 & 3.4 \\
\hline & $\mathrm{Std} \%$ & 3.0 & 3.6 & 3.6 & 4.9 & 2.1 & 1.9 & 3.8 \\
\hline & 90 days & 5.3 & 4.2 & 3.7 & 4.2 & 4.3 & 4.5 & 4.5 \\
\hline & $\mathrm{Std} \%$ & 2.6 & 3.4 & 2.5 & 3.8 & 6.8 & 4.4 & 3.7 \\
\hline Static Elastic & 28 days & 29,000 & 28,267 & 27,333 & 25,333 & 28,600 & 25,400 & 24,800 \\
\hline Modulus, E (MPa) & $\mathrm{Std} \%$ & 5.2 & 0.8 & 5.0 & 0.8 & 2.5 & 5.5 & 2.7 \\
\hline
\end{tabular}

When VP is used in the absence of RCA (series VP5-RCA0, VP10-RCA0, VP15-RCA0), the compressive strength decreased when the replacement percentage increased, especially when the percentage is over 10\%. After 28 curing days, the concretes with $5 \%, 10 \%$ and $15 \%$ replacements presented compressive strength losses of $5 \%, 15 \%$ and $33 \%$ compared to the CC value. These results agree with those from previous studies [12,14]. However, after 90 curing days, a decrease was noted in the strength losses (Figure 7) and the specimens with 5\%, 10\% and 15\% VP replacements presented differences of $+2 \%,-3 \%$ and $-21 \%$, respectively.

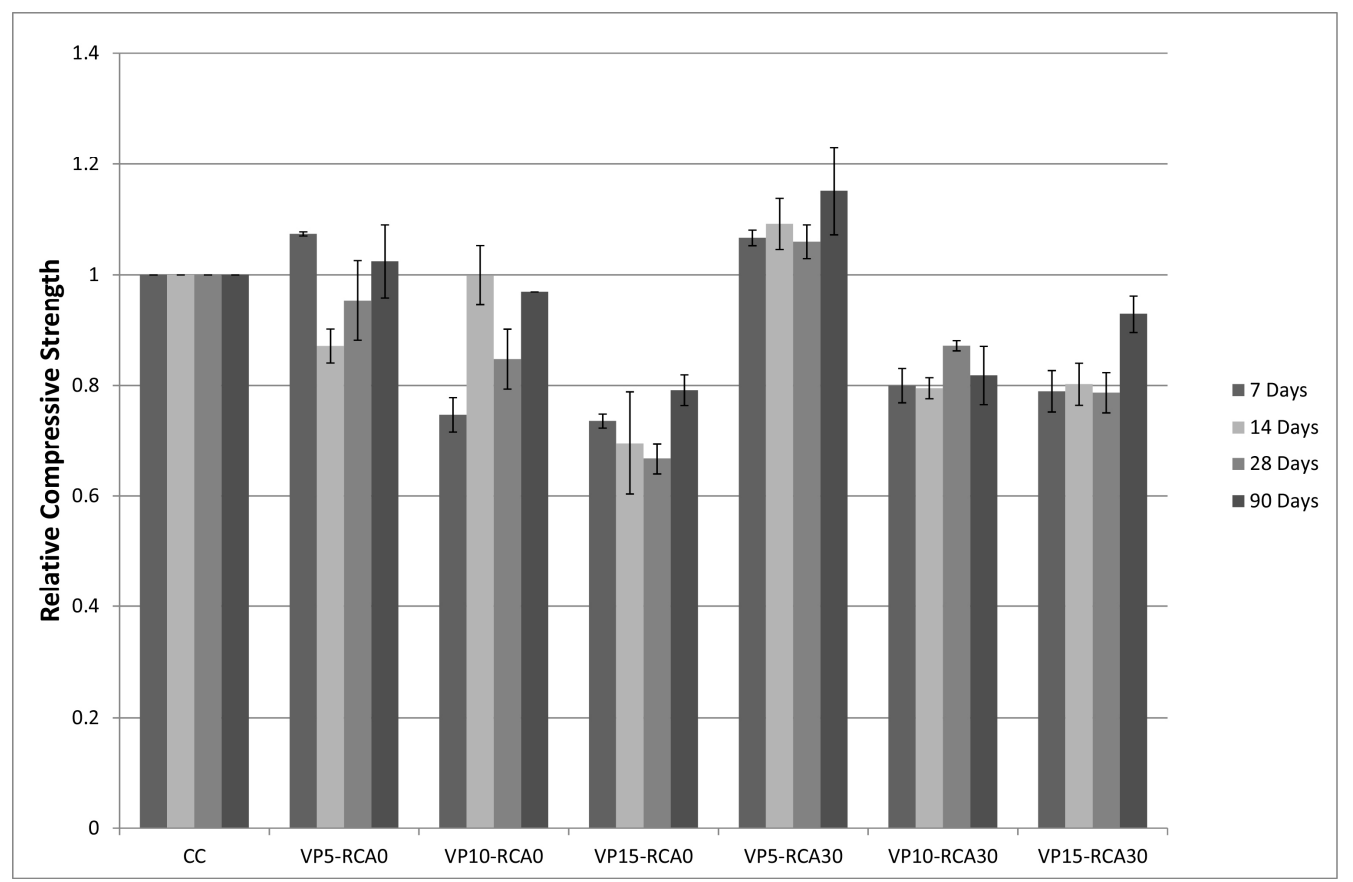

Figure 7. Variation of compressive strength compared to control concrete (CC).

A similar behavior has been observed when both residues were used simultaneously (series VP5-RCA30, VP10-RCA30, VP15-RCA30). The most important losses in the compressive strength were 
observed when over $10 \%$ of cement was is replaced for VP. After 28 curing days, the concretes with $5 \%, 10 \%$ and $15 \%$ VP replacements showed strength differences of $+6 \%,-13 \%$ and $-21 \%$ respectively compared to the CC values. However, after 90 curing days, a significant reduction was observed in these differences (Figure 7), since the concretes with 5\%, 10\% and 15\% VP replacements showed differences of $+15 \%,-18 \%$ and -7 compared to CC values.

Figure 8 analyses the development of the strength with the curing days.

Compared to CC, recycled concretes presented a higher gaining rate after 28 curing days. CC shows a $20 \%$ strength increase after 28 curing days, whereas concretes without RCA but with VP replacement showed strength gaining rates after 28 days, which increased with the amount of VP, with values of $26 \%, 31 \%$ and $33 \%$ for the series VP5-RCA0, VP10-RCA0 and VP15-RCA0, respectively. After 28 curing days, concretes with both recycled materials presented gaining rates of $27 \%, 15 \%$ and $33 \%$ for the series VP5-RCA30, VP10-RCA30 and VP15-RCA30, respectively. The strength increase after a relatively long curing time (90 days) for concretes with both recycled materials could be attributed to the pozzolanic reaction between the reactive silica in the VP and free $\mathrm{Ca}(\mathrm{OH})_{2}$ at late ages. Labbaci et al. [2] reported equivalent results, concluding that VP improves compressive strength because it produces a secondary calcium silicate hydrate(C-S-H) reaction. During the hydration process of cement, the reaction between free $\mathrm{Ca}(\mathrm{OH})_{2}$ and VP leads to a more impermeable matrix because of the refinement of the pore structure [12,14,39]. Consequently, the compressive strengths of concretes containing VP are comparable to those of the control concrete for long-term curing.

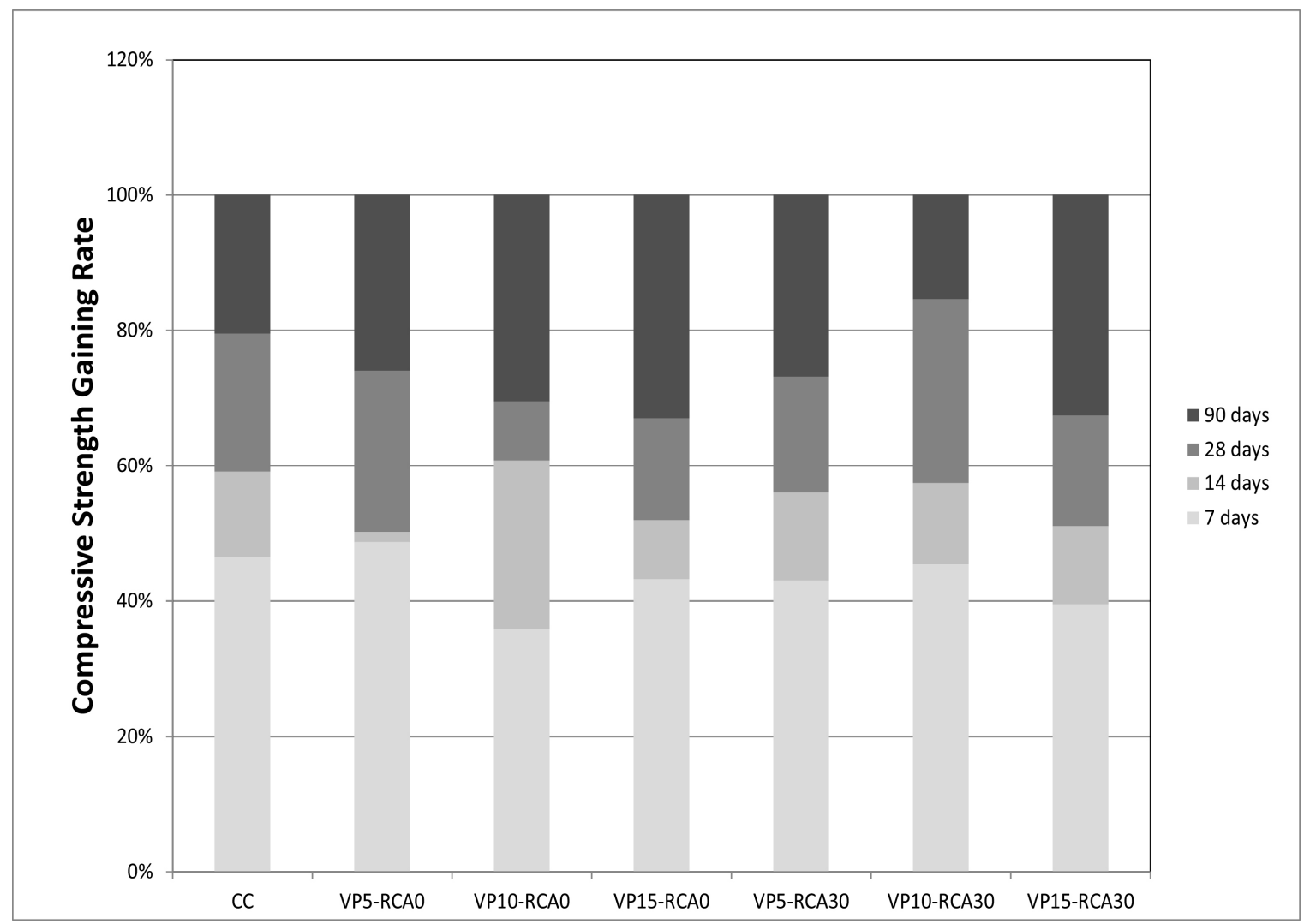

Figure 8. Compressive strength gaining rate with the curing time.

Furthermore, a remarkable effect occurs when studying the combination of 5\% VP replacement and 30\% RCA (samples VP5-RCA30). Results showed how (see Figure 7) this combination seems not only to avoid strength losses but strengthens the concrete. Hossain and Lachemi [39] considered that the pozzolanic reactivity of VP consumes the calcium hydroxide that results from the cement hydration. The silica content of the supplementary cementitious materials reacts with the calcium hydroxide 
present, not only in the cement but also in the mortar that remains adhered to the RCA [40,41], increasing this effect and making the VP capable of compensating for the weaknesses produced by the RCA. Following this hypothesis and in view of the results obtained, there is an optimal percentage of VP replacement, after which the microstructure enhancement is no longer possible and the strengthening of the material ceases. From the results found here, this optimal content may vary depending on the nature of the aggregates used.

\subsection{Flexural Strength}

Results are shown in Table 5 and Figure 9.

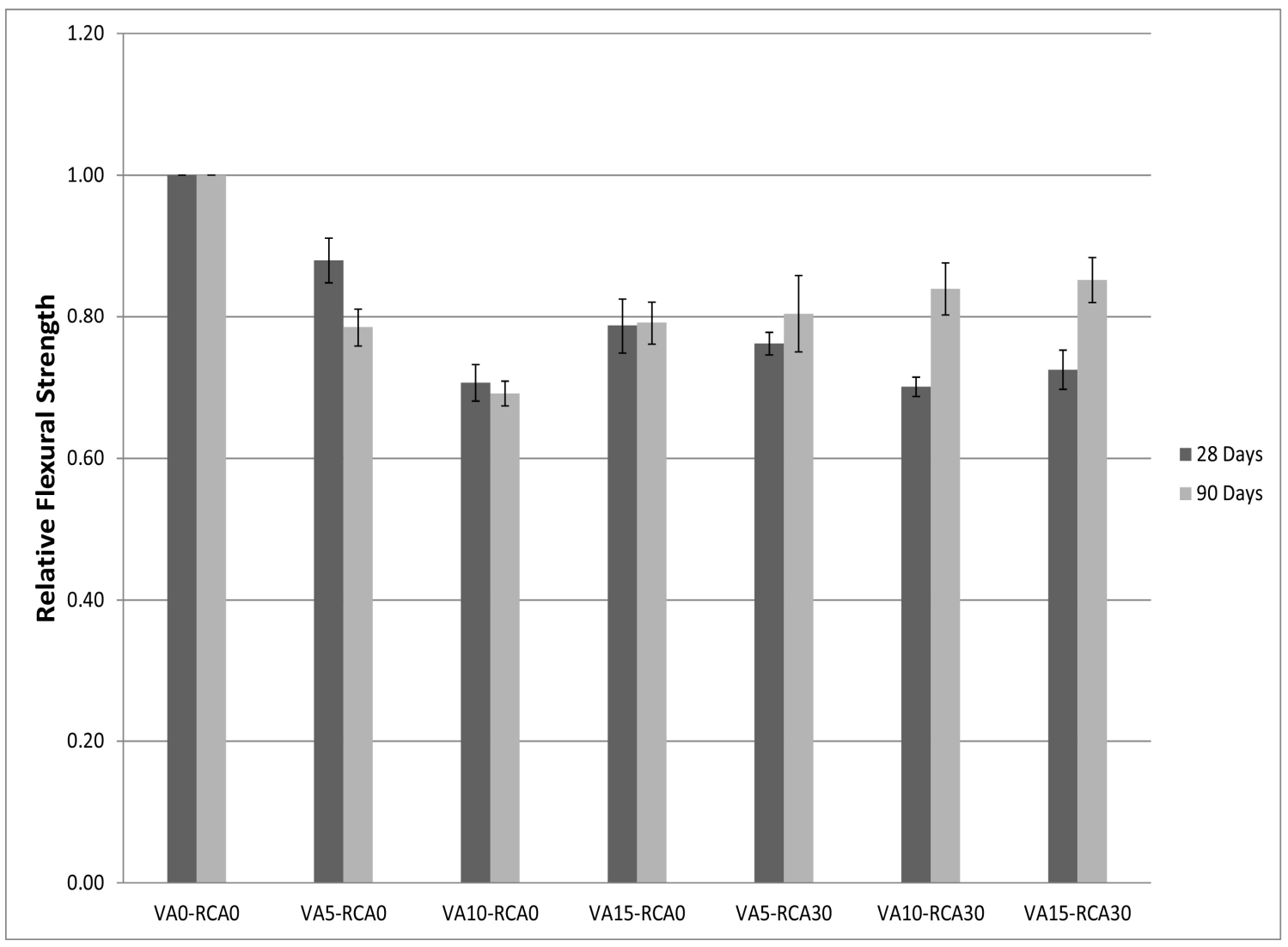

Figure 9. Relative flexural strength, compared to control concrete (CC).

When VP was used with no RCA, the flexural strength after 28 curing days presented losses compared to CC values of $12 \%, 29 \%$ and $21 \%$ for the series VP5-RCA0, VP10-RCA0, VP15-RCA0, respectively (Figure 9). After 90 curing days, the losses for those series increased up to $22 \%, 31 \%$ and $21 \%$ respectively.

When both VP and RCA are used together, the flexural strength tested after 28 curing days presented higher losses than the CC, the values of which were $24 \%, 30 \%$ and $28 \%$ for the series VP5-RCA30, VP10-RCA30 and VP15-RCA30, respectively. These decreases can be attributed to the use of RCA. According to Puthussery et al. [42], this effect may be due to the water absorption capacity and the porous nature of RCA and the mortar adhered to their surfaces. Other studies agree with these hypotheses on the use of RCA [19,43], concluding that a loss of around 10\% seems unavoidable when the flexural strength is analysed, even though the compressive strength values may present no losses.

Increasing the curing time up to 90 days, these losses were reduced to $20 \%, 16 \%$ and $15 \%$ for the series VP5-RCA30, VP10-RCA30 and VP15-RCA30, respectively. With long-term curing, the amorphous silica present in the VP and the calcium hydroxide $\left(\mathrm{Ca}(\mathrm{OH})_{2}\right)$ present in the pores of the RCA mortar 
and the cement matrix, would react and form C-S-H, which enhances the strength of the mixture and improves the interface between the cement paste and the aggregates [44].

\subsection{Static Modulus of Elasticity}

The results are shown in Table 5 and Figure 10.

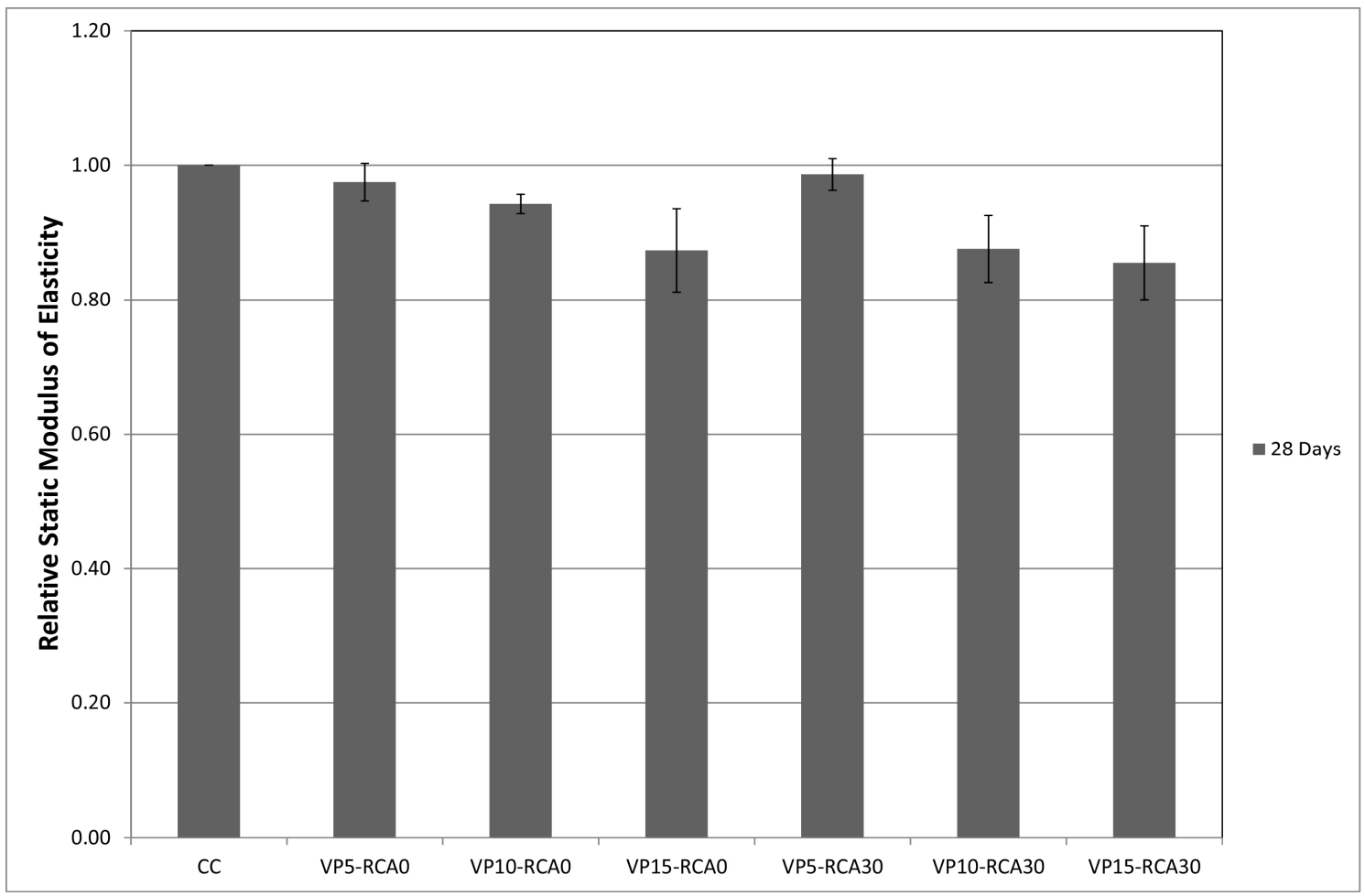

Figure 10. Relative static elastic modulus, compared to control concrete (CC).

For samples with no RCA, the static elastic modulus presented losses that varied from 3\% to $13 \%$ compared to CC values. These results reflect the low static elastic modulus of VP and its influence on the final material. Similar losses were found when VP is combined with RCA, varying between $15 \%$ and $26 \%$ with respect to CC.

\subsection{Comparison with Technical Regulations}

To compare the experimental behaviour of concrete made using recycled materials with the values estimated by technical regulations, the equations proposed by ACI 318 and Eurocode 2 (EC2) for evaluating the flexural strength and the static elastic modulus, calculated using the 28-day compressive strength, were used.

ACI 318 proposes the following equations:

$$
\begin{aligned}
& f_{r}=0.62 \sqrt{f^{\prime}{ }_{c}} \\
& E_{c}=4700 \sqrt{f^{\prime}{ }_{c}}
\end{aligned}
$$

EC2 proposes the following equations:

$$
f_{c t m, f l}=\max \left(\left(1.6-\frac{h}{1000}\right) f_{c t m}, f_{c t m}\right)
$$




$$
E_{c}=22\left(\frac{f_{c m}}{10}\right)^{0.30}
$$

where $f_{r}$ is the flexural strength; $E_{c}$ is the static elastic modulus; $f_{c}{ }_{c}$ is the compressive strength after 28 curing days; $f_{c t m}, f$ is the flexural strength following EC2; $h$ is the height of the specimen; and $f_{c t m}$ is the mean flexural strength obtained using $f_{c t m}=0.3\left(f_{c k}\right)^{2 / 3}$, where $f_{c k}$ are the experimental values obtained for the compressive strength minus $8 \mathrm{MPa}$.

Figure 11 shows the results obtained for the flexural strength applying Equations (2) and (4).

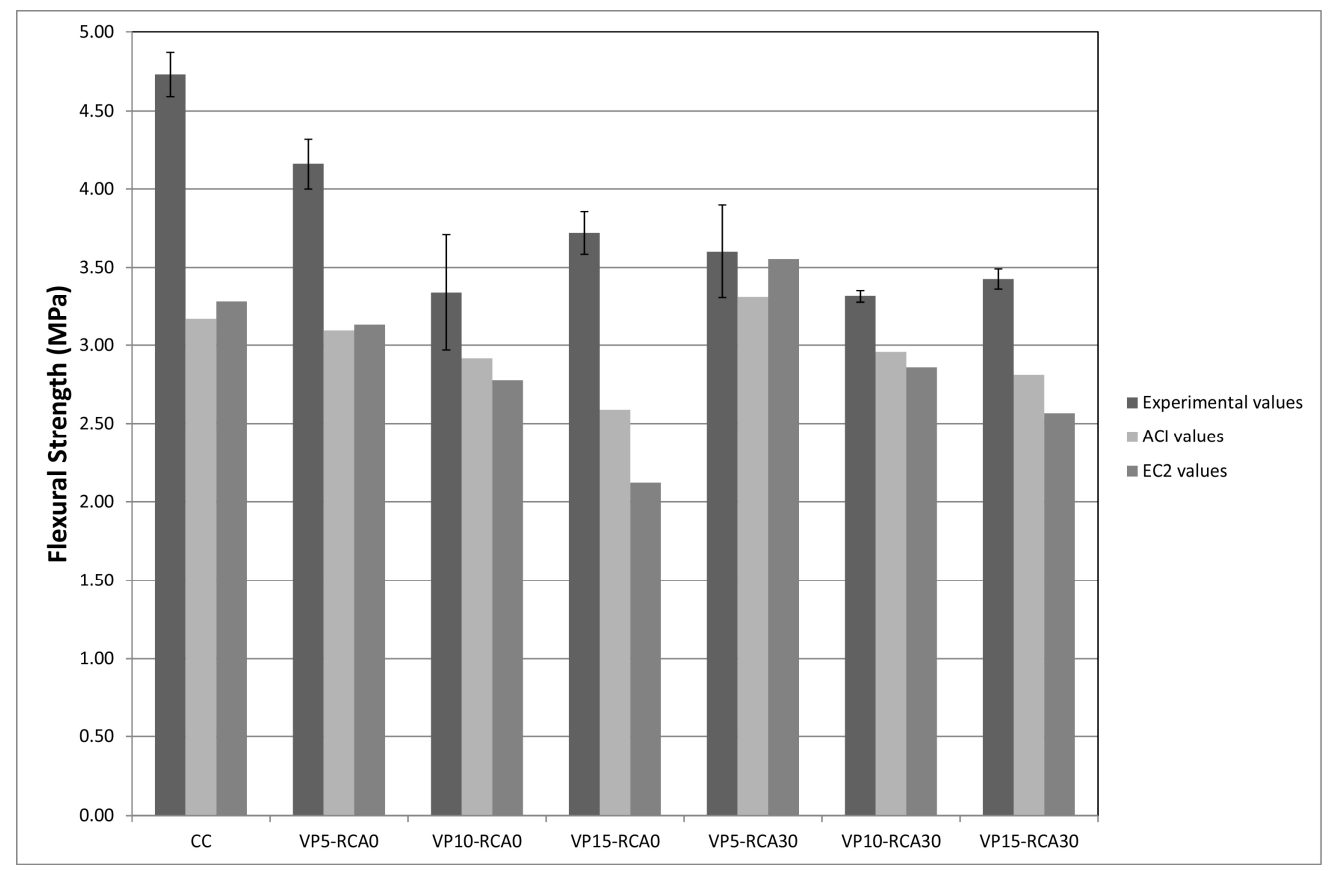

Figure 11. Comaparison of experimental flexural strength after 28 curing days with theoretical values proposed by ACI 318 and EC2.

Experimental values for CC were 49\% higher than those estimated using ACI (Equation (2)). When VP was used without RCA, the experimental values exceeded the theoretical ACI ones in the range of $15 \%$ to $44 \%$, whereas these values decreased when RCA was added to the mixture, limiting the increase in the flexural strength in the range of $9 \%$ to $22 \%$. Comparable results have been obtained for CC considering EC2 (Equation (4)); in this case, the increase was $44 \%$. When VP is used without RCA experimental values exceeded theoretical ACI ones in the range of $20 \%$ to $75 \%$, whereas these values decreased when RCA was added to the mixture, limiting the increase in the flexural strength the range of $1 \%$ to $34 \%$.

It has been demonstrated that many factors have an influence on the flexural strength, such as the size of the sample, the curing conditions, the type of binder and the strength level of the concrete [45]. Many researchers have studied the effects of each of these factors. Raphael [46] concluded that one of the reasons for the variations between the measured and estimated flexural strength values is that the equations used come from the elastic theory, which assumes an elastic behaviour of concrete until failure.

In this study, all the flexural strengths estimated by technical regulations were always lower than the values obtained experimentally, which would not produce an overvaluation of this parameter from a design point of view.

Figure 12 shows the results obtained for the static elastic modulus.

When the ACI (Equation (3)) was applied, experimental CC values were 21\% higher than the theoretical ones. When VP was used without RCA, experimental values were between $21 \%$ and $29 \%$ 
higher than theoretical ones. Again, these values decreased when RCA was added, being between $13 \%$ and $16 \%$. On the other hand, when applying EC2 (Equation (5)), experimental CC values were $1 \%$ lower than theoretical ones. When VP was used without RCA, experimental values were between $2 \%$ and 3\% lower than theoretical ones. This decrease became more significant (5\% and $10 \%)$ when RCA were added.

According to Vakhshouri and Nejadi [47], the elastic modulus depends on several parameters, such as the load conditions, the cement matrix characteristics, the properties of the interfacial transition zone, the elastic modulus of the aggregates and their volumetric fraction, among others. Therefore, the differences observed between the values of the elastic modulus estimated by the different codes or technical regulations could be due mainly to the fact that each code uses equations established according to the local characteristics of the concretes. In addition to this, when recycled materials are used, the codes are not always capable of predicting the behaviour of these concretes conservatively, making it necessary to consider special equations for designing structures with recycled concretes. In this work, the results reveal that the use of EC2 equations to estimate the static elastic modulus is not as conservative as desirable when recycled materials are incorporated into the concrete.

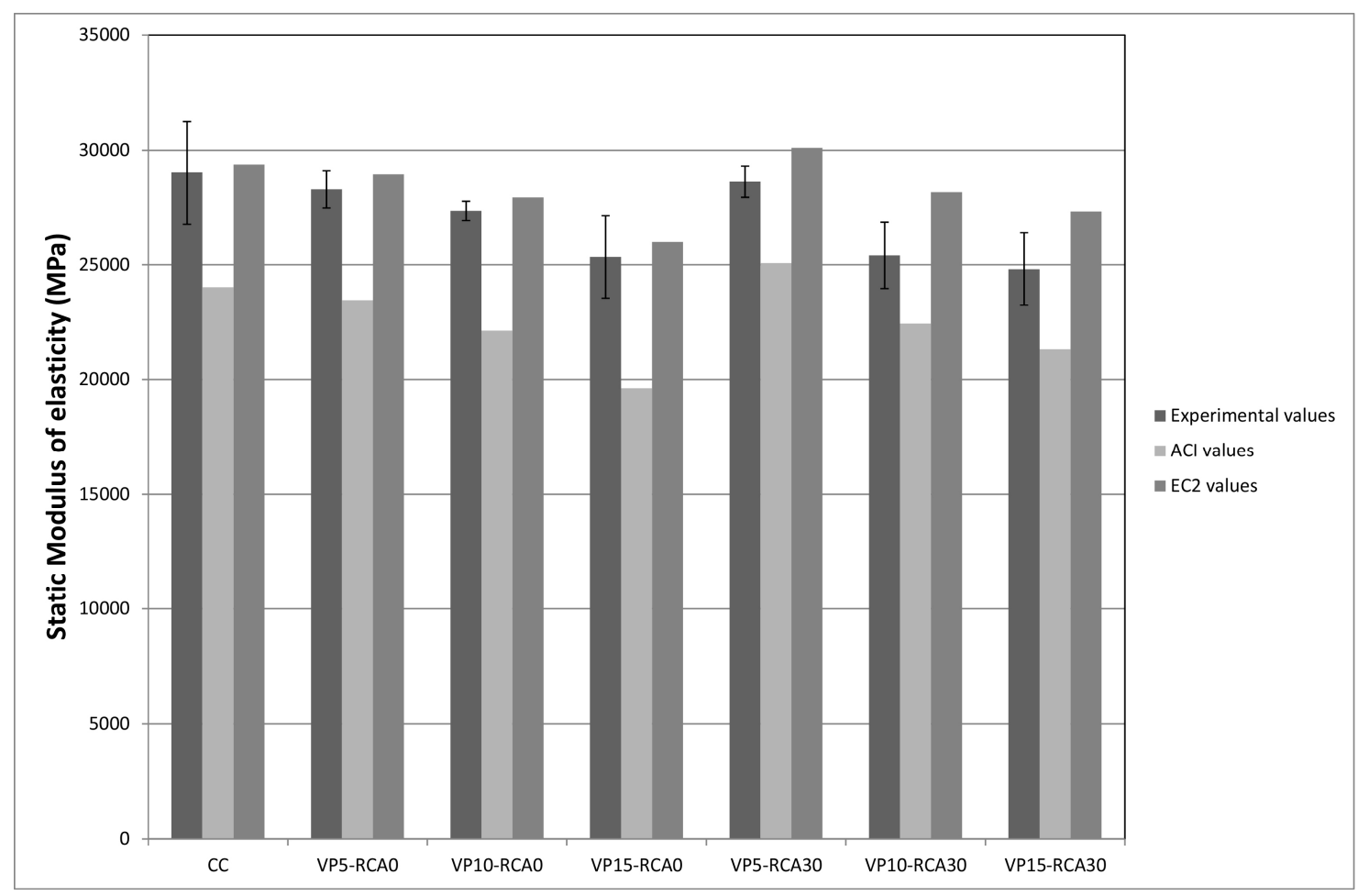

Figure 12. Comparison of experimental static elastic modulus with theoretical values proposed by ACI 318 and EC2.

\subsection{Greenhouse Gas (GHG) Assessment}

As can be observed in Figure 13, each 5\% increase of the VP content produces a reduction of approximately $4.4 \%$ in $\mathrm{CO}_{2}$ emissions. On the other hand, if $30 \%$ of RCA is included in the concrete, the $\mathrm{CO}_{2}$ emissions are reduced an additional $0.4 \%$.

Therefore, for the maximum replacement percentages analysed ( $30 \%$ RCA and $15 \% \mathrm{VP})$ in this work, $\mathrm{CO}_{2}$ emissions generated during the concrete manufacture process would be reduced by up to $13.6 \%$. 


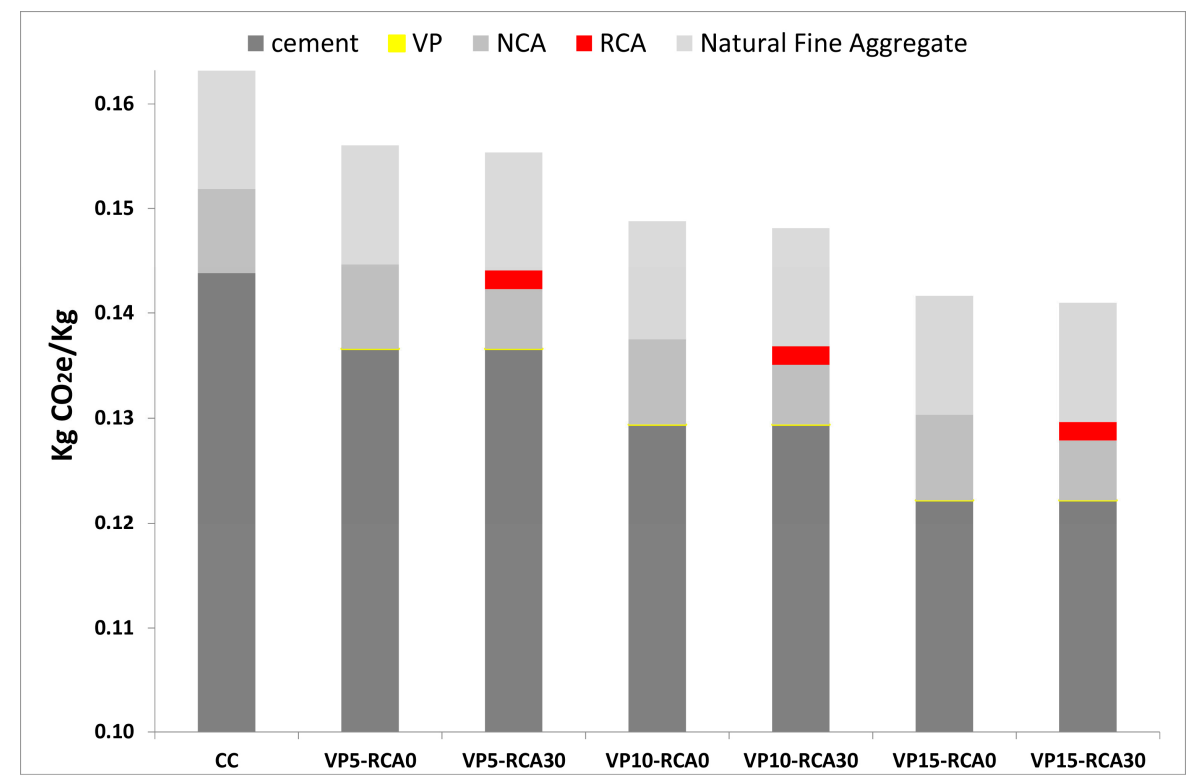

Figure 13. $\mathrm{CO}_{2}$ emissions for the concretes studied.

Results from the SUB-RAW index (Table 6) indicated that VP is much more sustainable than cement and according to Bontempi's interpretation of this index [27], the embodied energy and the $\mathrm{CO}_{2}$ footprint of VP is three orders of magnitude lower than those for cement, while NCA are slightly more sustainable than RCA due to their lower embodied energy.

Table 6. SUB-RAW index.

\begin{tabular}{cc}
\hline Compared Materials & SUB-RAW Index \\
\hline VP-Cement & 3.09 \\
RCA-NCA & -0.13 \\
\hline
\end{tabular}

\section{Conclusions}

The main conclusions that can be drawn from the results here can be summarized as follows:

- When VP is used without RCA, after 28 curing days compressive strength suffers significant losses compared to CC values when only $15 \%$ of the cement is replaced.

- When VP is used with RCA, after 28 curing days, the losses suffered by the compressive strength are significant over $10 \%$ replacement.

- All the series with recycled materials present higher gaining rates in their compressive strengths than the CC in the long term, which may be attributed to the secondary C-S-H reaction between the VP reactive silica and the free $\mathrm{Ca}(\mathrm{OH})_{2}$ that takes place at later ages.

- The strength losses due to the presence of RCA can be compensated by including small percentages of VP to the mixture.

- The presence of both residues involves a gaining rate in the flexural strength for long-term curing, likely due to the long-term secondary C-S-H reaction.

- The static elastic modulus shows losses due to the use of VP, regardless of the use of RCA.

- Equations proposed by ACI and EC2 for the flexural strength give lower values than the experimental ones for all the series.

- The equation proposed by ACI for the static elastic modulus gives lower values than the experimental ones for all the series. However, the equation proposed by EC2 for the static elastic modulus gives higher results than the experimental values for all the series. 
- The combined use of VP and RCA makes it possible to reduce up to $13.6 \%$ of $\mathrm{CO}_{2}$ emissions during the manufacture of concrete, considering that the RCA and NCA are transported from a distance of 15 and $100 \mathrm{~km}$, respectively.

- As raw material, VP is more sustainable than cement due to its lower required energy consumption, while the environmental assessment performed for RCA and NCA showed that the sustainable effect of both are very similar, although the $\mathrm{CO}_{2}$ emissions related to NCA can be higher than those considered in this work depending on their transport distances (greater than $100 \mathrm{~km})$.

- Results encourage further analysis to establish and quantify the combined effects of VP and RCA on the durability of recycled concretes.

Author Contributions: V.L. wrote the paper. V.L., P.M., E.T., B.I.H.-J. and J.M.O. performed the experiments. J.M.O. and G.M. supervised the research work and revised the paper. All the authors contributed to conceive and design the experiments and to analyse and discuss the results.

Funding: The research included in the paper has been financially supported by project DI17-0013, “Análisis del efecto de la trituraciónen el comportamiento del polvo de vidriocomoreemplazo de cemento", funded by the Universidad de La Frontera (Chile).

Conflicts of Interest: The authors declare no conflict of interest.

\section{References}

1. Hossain, M.U.; Xuan, D.; Poon, C.S. Sustainable management and utilisation of concrete slurry waste: A case study in Hong Kong. Waste Manag. 2017, 61, 397-404. [CrossRef] [PubMed]

2. Labbaci, Y.; Labbaci, B.; Abdelaziz, Y.; Mekkaoui, A.; Alouani, A. The use of the volcanic powders as supplementary cementitious materials for environmental-friendly durable concrete. Constr. Build. Mater. 2017, 133, 468-481. [CrossRef]

3. Williams, M.; Ortega, J.M.; Sánchez, I.; Cabeza, M.; Climent, M.A. Non-Destructive Study of the Microstructural Effects of Sodium and Magnesium Sulphate Attack on Mortars Containing Silica Fume Using Impedance Spectroscopy. Appl. Sci. 2017, 7, 648. [CrossRef]

4. Ortega, J.M.; Sánchez, I.; Climent, M.A. Influence of environmental conditions on durability of slag cement mortars. In Proceedings of the 2nd International Conference on Sustainable Construction Materials and Technologies, Ancona, Italy, 28-30 June 2010.

5. Cordeiro, G.C.; Toledo Filho, R.D.; Tavares, L.M.; Fairbairn, E.M.R. Experimental characterization of binary and ternary blended-cement concretes containing ultrafine residual rice husk and sugar cane bagasse ashes. Constr. Build. Mater. 2012, 29, 641-646. [CrossRef]

6. Rajamma, R.; Senff, L.; Ribeiro, M.J.; Labrincha, J.A.; Ball, R.J.; Allen, G.C.; Ferreira, V.M. Biomass fly ash effect on fresh and hardened state properties of cement based materials. Compos. Part B Eng. 2015, 77, 1-9. [CrossRef]

7. Güneyisi, E.; Gesoğlu, M.; Akoi, A.O.M.; Mermerdaş, K. Combined effect of steel fiber and metakaolin incorporation on mechanical properties of concrete. Compos. Part B Eng. 2014, 56, 83-91. [CrossRef]

8. Pastor, J.L.; Ortega, J.M.; Flor, M.; López, M.P.; Sánchez, I.; Climent, M.A. Microstructure and durability of fly ash cement grouts for micropiles. Constr. Build. Mater. 2016, 117, 47-57. [CrossRef]

9. Naceri, A.; Hamina, M.C. Use of waste brick as a partial replacement of cement in mortar. Waste Manag. 2009, 29, 2378-2384. [CrossRef] [PubMed]

10. Siddique, R. Properties of concrete made with volcanic ash. Resour. Conserv. Recycl. 2012, 66, 40-44. [CrossRef]

11. SeddikMeddah, M. Durability performance and engineering properties of shale and volcanic ashes concretes. Constr. Build. Mater. 2015, 79, 73-82. [CrossRef]

12. Hossain, K.M.A.; Lachemi, M. Strength, durability and micro-structural aspects of high performance volcanic ash concrete. Cem. Concr. Res. 2007, 37, 759-766. [CrossRef]

13. Anwar Hossain, K.M. Performance of volcanic ash based precast and in situ blended cement concretes in marine environment. J. Mater. Civ. Eng. 2005, 17, 694-702. [CrossRef] 
14. Hossain, K.M.A. Blended cement using volcanic ash and pumice. Cem. Concr. Res. 2003, 33, 1601-1605. [CrossRef]

15. Faleschini, F.; Zanini, M.A.; Pellegrino, C.; Pasinato, S. Sustainable management and supply of natural and recycled aggregates in a medium-size integrated plant. Waste Manag. 2016, 49, 146-155. [CrossRef] [PubMed]

16. Ghanbari, M.; Monir Abbasi, A.; Ravanshadnia, M. Economic and Environmental Evaluation and Optimal Ratio of Natural and Recycled Aggregate Production. Adv. Mater. Sci. Eng. 2017, 2017. [CrossRef]

17. Tam, V.W.Y.; Gao, X.F.; Tam, C.M.; Ng, K.M. Physio-chemical reactions in recycle aggregate concrete. J. Hazard. Mater. 2009, 163, 823-828. [CrossRef] [PubMed]

18. Ismail, S.; Ramli, M. Engineering properties of treated recycled concrete aggregate (RCA) for structural applications. Constr. Build. Mater. 2013, 44, 464-476. [CrossRef]

19. Bui, N.K.; Satomi, T.; Takahashi, H. Improvement of mechanical properties of recycled aggregate concrete basing on a new combination method between recycled aggregate and natural aggregate. Constr. Build. Mater. 2017, 148, 376-385. [CrossRef]

20. Tam, V.W.Y.; Gao, X.F.; Tam, C.M. Microstructural analysis of recycled aggregate concrete produced from two-stage mixing approach. Cem. Concr. Res. 2005, 35, 1195-1203. [CrossRef]

21. Sáez del Bosque, I.F.; Zhu, W.; Howind, T.; Matías, A.; Sánchez de Rojas, M.I.; Medina, C. Properties of interfacial transition zones (ITZs) in concrete containing recycled mixed aggregate. Cem. Concr. Compos. 2017, 81, 25-34. [CrossRef]

22. Kang, M.; Weibin, L. Effect of the aggregate size on strength properties of recycled aggregate concrete. Adv. Mater. Sci. Eng. 2018. [CrossRef]

23. Tam, V.W.Y.; Wang, K.; Tam, C.M. Assessing relationships among properties of demolished concrete, recycled aggregate and recycled aggregate concrete using regression analysis. J. Hazard. Mater. 2008, 152, 703-714. [CrossRef] [PubMed]

24. Li, X. Recycling and reuse of waste concrete in China. Part II. Structural behaviour of recycled aggregate concrete and engineering applications. Resour. Conserv. Recycl. 2009, 53, 107-112. [CrossRef]

25. Qasrawi, H.; Marie, I. Towards better understanding of concrete containing recycled concrete aggregate. Adv. Mater. Sci. Eng. 2013. [CrossRef]

26. Centro de Estudos y Experimentación de ObrasPúblicas (CEDEX) Residuos de Construcción y Demolición. Normativatécnica. Available online: http:/ / www.cedexmateriales.es/catalogo-de-residuos/35/residuosde-construccion-y-demolicion/223/normativa-tecnica.html (accessed on 7 August 2018).

27. Bontempi, E. A new approach for evaluating the sustainability of raw materials substitution based on embodied energy and the $\mathrm{CO}_{2}$ footprint. J. Clean. Prod. 2017, 162, 162-169. [CrossRef]

28. Romero, J.E.; Morgavi, D.; Arzilli, F.; Daga, R.; Caselli, A.; Reckziegel, F.; Viramonte, J.; Díaz-Alvarado, J.; Polacci, M.; Burton, M.; et al. Eruption dynamics of the 22-23 April 2015 Calbuco Volcano (Southern Chile): Analyses of tephra fall deposits. J. Volcanol. Geotherm. Res. 2016, 317, 15-29. [CrossRef]

29. Reckziegel, F.; Bustos, E.; Mingari, L.; Báez, W.; Villarosa, G.; Folch, A.; Collini, E.; Viramonte, J.; Romero, J.; Osores, S. Forecasting volcanic ash dispersal and coeval resuspension during the April-May 2015 Calbuco eruption. J. Volcanol. Geotherm. Res. 2016, 321, 44-57. [CrossRef]

30. Fathifazl, G.; Abbas, A.; Razaqpur, A.G.; Isgor, O.B.; Fournier, B.; Foo, S. New mixture proportioning method for concrete made with coarse recycled concrete aggregate. J. Mater. Civ. Eng. 2009, 21, 601-611. [CrossRef]

31. Berndt, M.L. Properties of sustainable concrete containing fly ash, slag and recycled concrete aggregate. Constr. Build. Mater. 2009, 23, 2606-2613. [CrossRef]

32. Omary, S.; Ghorbel, E.; Wardeh, G. Relationships between recycled concrete aggregates characteristics and recycled aggregates concretes properties. Constr. Build. Mater. 2016, 108, 163-174. [CrossRef]

33. Hammond, G.P.; Jones, C.I. Embodied energy and carbon in construction materials. Proc. Inst. Civ. Eng. Energy 2008, 161, 87-98. [CrossRef]

34. OECD Climate Change Mitigation Policies. Available online: http://www.compareyourcountry.org/ climate-policies?cr=oecd $\backslash$ protect $\backslash \mathrm{T} 1 \backslash$ textbraceleft $\$ \backslash$ delimiter"026E30F\$\& $\backslash$ protect $\backslash \mathrm{T} 1 \backslash$ textbracerightlg= en \protect $\backslash \mathrm{T} 1 \backslash$ textbraceleft $\backslash$ delimiter"026E30F\$\& \protect $\backslash \mathrm{T} 1 \backslash$ textbracerightpage $=2 \backslash$ protect $\backslash \mathrm{T} 1 \backslash$ textbraceleft $\$ \backslash$ delimiter"026E30F\$\& \protect $\backslash \mathrm{T} 1 \backslash$ textbracerightvisited=1 (accessed on 28 July 2018).

35. Fraj, A.B.; Idir, R. Concrete based on recycled aggregates-Recycling and environmental analysis: A case study of paris' region. Constr. Build. Mater. 2017, 157, 952-964. [CrossRef] 
36. Quattrone, M.; Angulo, S.C.; John, V.M. Energy and $\mathrm{CO}_{2}$ from high performance recycled aggregate production. Resour. Conserv. Recycl. 2014, 90, 21-33. [CrossRef]

37. UK Government. Department for Business, Energy \& Industrial Strategy. Government Emission Conversion Factors for Greenhouse Gas Company Reporting. Available online: https://www.gov.uk/government/ collections / government-conversion-factors-for-company-reporting (accessed on 7 August 2018).

38. Silva, J.; Brito, J.D.; Veiga, R. Incorporation of fine ceramics in mortars. Constr. Build. Mater. 2009, 23, 556-564. [CrossRef]

39. Hossain, K.M.A.; Lachemi, M. Performance of volcanic ash and pumice based blended cement concrete in mixed sulfate environment. Cem. Concr. Res. 2006, 36, 1123-1133. [CrossRef]

40. Letelier, V.; Tarela, E.; Muñoz, P.; Moriconi, G. Assessment of the mechanical properties of a concrete made by reusing both: Brewery spent diatomite and recycled aggregates. Constr. Build. Mater. 2016, 114, 492-498. [CrossRef]

41. Letelier, V.; Tarela, E.; Muñoz, P.; Moriconi, G. Combined effects of recycled hydrated cement and recycled aggregates on the mechanical properties of concrete. Constr. Build. Mater. 2017, 132, 365-375. [CrossRef]

42. Puthussery, J.V.; Kumar, R.; Garg, A. Evaluation of recycled concrete aggregates for their suitability in construction activities: An experimental study. Waste Manag. 2017, 60, 270-276. [CrossRef] [PubMed]

43. Ikeda, T.; Yamane, S.; Sakamoto, A. Strengths of concrete containing recycled concrete aggregate. In Demolition and Reuse of Concrete and Masonry; Kasai, Y., Ed.; Chapman and Hall: Tokyo, Japan, 1988; pp. 585-594.

44. Nassar, R.-U.-D.; Soroushian, P. Strength and durability of recycled aggregate concrete containing milled glass as partial replacement for cement. Constr. Build. Mater. 2012, 29, 368-377. [CrossRef]

45. Ahmed, M.; El Hadi, K.M.; Hasan, M.A.; Mallick, J.; Ahmed, A. Evaluating the co-relationship between concrete flexural tensile strength and compressive strength. Int. J. Struct. Eng. 2014, 5, 115-131. [CrossRef]

46. Raphael, J.M. Tensile strength of concrete. J. Am. Concr. Inst. 1984, 81, 158-165.

47. Vakhshouri, B.; Nejadi, S. Empirical models and design codes in prediction of modulus of elasticity of concrete. Front. Struct. Civ. Eng. 2018. [CrossRef]

(C) 2018 by the authors. Licensee MDPI, Basel, Switzerland. This article is an open access article distributed under the terms and conditions of the Creative Commons Attribution (CC BY) license (http://creativecommons.org/licenses/by/4.0/). 